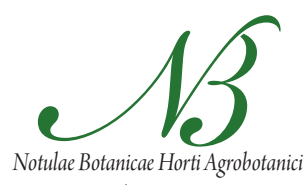

Cluj-Napoca

\title{
Rapid Quantitative Analysis of Ethanol and Prediction of Methanol Content in Traditional Fruit Brandies from Romania, using FTIR Spectroscopy and Chemometrics
}

\author{
Teodora Emilia COLDEA ${ }^{1}$, Carmen SOCACIU¹ , Florinela FETEA ${ }^{1}$, \\ Floricuța RANGA', Raluca Maria POP' ${ }^{1}$, Mira FLOREA ${ }^{2 *}$ \\ ${ }^{1}$ University of Agricultural Sciences and Veterinary Medicine, Faculty of Food Science and Technology, 400372 Cluj-Napoca, Romania \\ ${ }^{2}$ University of Medicine and Pharmacy "I. Hatieganu", Dept. of Community Medicine, Cluj- \\ Napoca, Romania; miraflorea@yahoo.com ( ${ }^{*}$ corresponding author)
}

\begin{abstract}
Fourier Transform Infrared (FTIR) spectroscopy in combination with chemometrics were applied for the quality control of 26 fruit brandies made by traditional technology in Romania. Firstly, for the identification and quantitative evaluation of methanol and ethanol in such samples, 4 mixtures of methanol and ethanol standard solutions and a spiked sample were fingerprinted in the 1200 - 950 $\mathrm{cm}^{-1}$ FTIR spectral range, identifying specific wavelength of 1020 and 1112 for methanol, 1047 and 1087 for ethanol. Then, the FTIR spectra of all brandy samples in the range $3500-750 \mathrm{~cm}^{-1}$ was registered and the methanol and ethanol concentrations were determined according to the previous calibration. By PCA (Principal component analysis) of FTIR areas $\left(1170-1000 \mathrm{~cm}^{-1}\right)$, the variability and discrimination between samples was possible, discriminating between the biological and geographical origin of brandy samples. Based on peak areas and intensities, it was predicted the concentration of methanol in all samples, using Partial least squares regression (PLS). The correlation between FTIR and the reference method (GC-FID) was well correlated and significant $(p<0.05)$. It was demostrated that FTIR technique offer a good prediction and statistical correlation with GC-FID technique for methanol quantification.
\end{abstract}

Keywords: ethanol, fruit brandies, FTIR, methanol, PCA, PLS, Romania

\section{Introduction}

The Central and East European countries have an old tradition in producing different types of fruit brandies. In Romania, there is a great interest to produce home-made traditional fruit brandies obtained by a double distillation of fermented fruits. Ţuica and pălinca are the two most popular, traditional distilled fruit beverages made from plums or apples, pears, other fruits respectively. Besides their volatile composition, the principal differences of these two types of fruit brandies are the ethanol content which reaches values between 24 up to $86 \% \mathrm{v} / \mathrm{v}$, for tuica, and 40 up to $70 \% \mathrm{v} / \mathrm{v}$, for pălinca. The determination of methanol in these types of fruit brandies it is an important approach, related to its safety for consumers. Depending of the type of fruit brandy, the maximum accepted methanol content was established to be $1350 \mathrm{mg} / 100 \mathrm{ml}$ anhydrous alcohol and in the case of țica and pălinca, the methanol content should not exceed $1200 \mathrm{mg} / 100 \mathrm{ml}$ anh. alc. (REG. 110/2008).

In the context of quality control of alcoholic beverages a range of different analytical methods are used, such as distillation and picnometry (Tešević et al., 2009), electronic densimetry (Coldea et al., 2011), colorimety (Joshi and Sandhu, 2000), photometry (Borges Sivanildo et al., 2006), by fluorescent chemical sensor (Bozkurt et al., 2010). The most advanced techniques are the chromatographic ones, either GC-FID, GC-MS or HPLC (Diban et al., 2009; García-Llobodanin et al., 2008; HernándezGómez et al., 2005; López-Vázquez et al., 2010; Wang et al., 2003). The last years, the expensive reference methods are replaced by simpler ones, non-destructive, easy to handle. The FTIR (Fourier Transform Infrared Spectroscopy) technique, in combination with chemometrics is such a fast and reproducible way to identify the authenticity and adulteration of different food and beverage products (Da Costa et al., 2004; Mansor et al., 2011; Rohman et al., 2010). The FTIR is increasenly used for the determination of methanol in alcoholic beverages (Arzberger and Lachenmeier, 2008; Gallignani et al., 2005; Lachenmeier, 2007; Mehrotra et al., 2005; Nagarajan et al., 2006; PérezPonce et al., 1998) or to verify the authenticity of different fruit juices (Leopold et al., 2011). The Near-Infrared (NIR) spectroscopy was also used to estimate the ethanol content in alcoholic beverages or to verify the adulteration of different beverages (Ashok et al., 2011; Pontes et al., 2006). 
144

In our previous studies we determined the ethanol and methanol content of brandies by electronic densimetry and by GC-FID techniques, respectively (Coldea $e t$ al., 2011).

In this study we realized the FTIR fingerprint of distilled fruit brandies in order to verify their authenticity, to identify the specific signals for methanol and ethanol, to apply the non-targeted PCA chemometric analysis for the evidence of three types of fruit brandies, to verify the plum brandy (tuica) authenticity from different regions and to predict methanol concentration by applying the PLS (Partial Least Squares) regression. We also compared the results obtained by FTIR method and by GC-FID technique or densimetic method.

\section{Materials and methods}

\section{Reagents}

Highly pure methanol (Merck, Germany, 99.8\% purity) and ethanol (Merck, Germany, 99.9\% purity) were used.

\section{Sampling}

A total number of 26 samples of fruit brandies (plum - tuica, apple and pear pălinca) originating from different Counties of Transylvania - Maramureş (MM), Cluj (CJ), Bistrița Năsăud (BN), Alba $(\mathrm{AB})$, Bihor $(\mathrm{BH})$ were collected from producers. All brandies were produced by traditional method: fermentation in wood barrels and double distilled in copper alembic, kept in wood or glass barrels for maturation. They were kept in glass recipients until analysis. Tab. 1 includes the sample denominations and their region of origin.

\section{Fourier Transform Infrared Spectroscopy}

To evaluate the content of methanol, we spiked one sample (P10) with methanol in different proportions, in order to identify the spectra modifications. There were used individually pure ethanol, pure methanol, sample P10 and different concentrations of methanol added to sample P10 at ratios P10:methanol of 1:1, 10:1, 10:0.5, 10:0.25, 9:1, 8:2, 8:4, 8:6. The FTIR spectra were registered in the range 1000 to $1200 \mathrm{~cm}^{-1}$, using Attenuated Transmission (ATR) and an internal reflection accessory made of Composite Zinc Selenide ( $\mathrm{ZnSe}$ ) and Diamond crystals (Shimadzu IR Prestige-21 equipment). For each sample, spectrum was registered from $3500-750 \mathrm{~cm}^{-1}$, and based on the ethanol and methanol specific wavenumbers, in all samples, the methanol and ethanol content was determined.

\section{Statistic and chemometric analysis}

Based on FTIR spectra and the frequency intensities recorded in the domain $1170-1000 \mathrm{~cm}^{-1}$, the chemometric analysis was performed. By Principal Component Analysis (PCA), using the Unscrambler 10.1 Software, version 10.1 (Camo Software AS, Oslo, Norway) the variability and discrimination between samples was made. Based on peak areas, from 1170 to $1000 \mathrm{~cm}^{-1}$, the concentration of methanol in samples was predicted by PLS regression. For each type of fruit brandy and each region for plum brandy a correlation analysis it was developed using Origin software (OriginLab, version 8.0).

\section{Reference Procedures}

Both, ethanol and methanol content of the same samples were previously determined. Ethanol content was analyzed in all samples by densimetric method. Methanol was evaluated by gas chromatography coupled with flame ionization detector (Coldea et al., 2011).

\section{Results and discussion}

Identification of methanol and ethanol in the FTIR spectra of pure standards and a spiked sample

The identification of methanol and ethanol was done, firstly, by applying the calibration curve using pure standards, as well mixtures of methanol:ethanol $(1: 1 ; 1: 9)$ (Fig. 1). Thus, pure methanol solution has the characteristic vibration frequency at $1020 \mathrm{~cm}^{-1}$ (major signal) and $1112 \mathrm{~cm}^{-1}$ (minor signal), while ethanol had the characteristic frequency at $1047 \mathrm{~cm}^{-1}$ (major signal) and $1087 \mathrm{~cm}^{-1}$ (minor signal). We selected the absorbances of major and minor signals specific for pure methanol and ethanol (Tab. 2). The approximate ratio of the absorbances of major $/ \mathrm{mi}$ nor signals in methanol was 5.2 and for ethanol 1.5. These frequencies are specific for stretching vibrations of $\mathrm{C}-\mathrm{O}$ bonds in these molecules.

Using methanol and ethanol in ratios of 1:9, or 1:1 respectively (Fig. 1) we noticed that the increase of metha-

Tab. 1. Numbering of fruit brandy samples (plum - P, apple - M, pear - PE brandies) and the provenience regions ( CJ-Cluj; MM- Maramureș; BH-Bihor; BN- Bistrița Năsăud)

\begin{tabular}{ccccccccccc}
\hline Sample no. & Region & Sample no. & Region & Sample no. & Region & Sample no. & Region & Sample no. & Region \\
\hline P1 & & P5 & & P3 & & M19 & BN & PE23 & CJ \\
P2 & & P7 & & P12 & & M20 & AB & PE24 & MM \\
P4 & CJ & P8 & & P13 & P13 & BN & M21 & CJ & PE25 & BN \\
P6 & & P9 & MM & P14 & & M22 & BH & PE26 & CJ \\
P17 & & P10 & & P15 & & & & & \\
P18 & & P11 & & P16 & & & & \\
\hline
\end{tabular}


Tab. 2. The values and ratios of the absorbance intensities (A) and areas ( B) of the minor and major signals specific for methanol $\left(1020\right.$ and $\left.1112 \mathrm{~cm}^{-1}\right)$ and ethanol $\left(1047\right.$ and $\left.1087 \mathrm{~cm}^{-1}\right)$

\begin{tabular}{|c|c|c|c|c|c|c|}
\hline Mixture/wavenumber $\left(\mathrm{cm}^{-1}\right)$ & 1020 & 1112 & 1047 & 1087 & $1020 / 1047$ & $1112 / 1087$ \\
\hline \multicolumn{7}{|c|}{ A } \\
\hline Methanol & 2.1470 & 0.4125 & - & - & - & - \\
\hline Ethanol & - & - & 1.9539 & 1.3448 & 1.1 & 0.3 \\
\hline Methanol:Ethanol 1:9 & - & - & 1.9484 & 1.2658 & - & - \\
\hline Methanol:Ethanol 1:1 & 1.9286 & - & 1.6314 & 0.9471 & 1.2 & - \\
\hline \multicolumn{7}{|c|}{ B } \\
\hline Methanol & 78.45 & 27.99 & - & - & - & - \\
\hline Ethanol & - & - & 73.76 & 53.21 & 1.1 & 0.5 \\
\hline Methanol:Ethanol 1:9 & - & - & - & - & - & - \\
\hline Methanol:Ethanol 1:1 & 76.46 & - & 30.26 & 44.41 & 2.5 & - \\
\hline
\end{tabular}

nol in the mixture, determine decreases of absorbance at 1047 and $1087 \mathrm{~cm}^{-1}$ and increase of absorbance at 1030 $1020 \mathrm{~cm}^{-1}$ and $1112 \mathrm{~cm}^{-1}$. Based on these observations, we consider the parameters which can identify and quantify the concentration of methanol in samples, are the ratios $\mathrm{A}_{1020} / \mathrm{A}_{1047}$ and $\mathrm{A}_{1112} / \mathrm{A}_{1087^{\circ}}$. Therefore were selected the areas corresponding to major and minor signals specific for pure methanol and ethanol (Tab. 3).

To illustrate the effect of the presence of methanol and its limit of detection in samples of brandies, it was chosen sample P10 (Fig. 2). By a controlled adulteration of the sample, were added various concentrations of pure methanol $2.5 \% ; 5 \% ; 9 \% ; 20 \% ; 33 \%$; $43 \%$ and $50 \%$, and noticed the gradual increase of intensity frequencies at 1112 and $1020 \mathrm{~cm}^{-1}$. The gradual evolution of methanol and ethanol signals of absorbtion at $1047,1087,1020$ and $1112 \mathrm{~cm}^{-1}$ is represented in Tab. 3 .

Therefore, the FTIR technique was useful not only to identify and quantify the ethanol, but also to recognize the presence of methanol and to determine the ratio between ethanol and methanol.

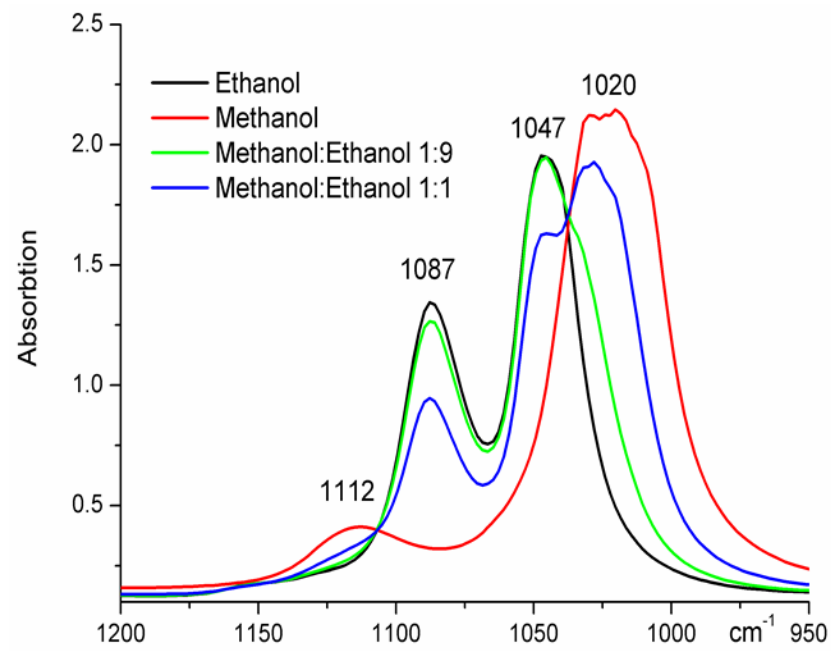

Fig. 1. The specific IR spectra for methanol and ethanol, as pure substances and in different concentration in mixture methanol:ethanol
Identification of ethanol by FTIR fingerprinting of brandy samples

FTIR spectroscopy can be used as potential means for quantitative analysis of fruit brandies, considered as a "fingerprinting tool", which means that there are no two fruit brandies samples with the same FTIR spectra, either in the number of peaks or in the absorbance of the maximum peak. Fig. 3 (up) exhibits the general FTIR spectra of 3 representative brandy samples (M21, PE25 and P5) in a region range of $3500-750 \mathrm{~cm}^{-1}$, showing quite similar fingerprints of these three samples in the region 1700-900 $\mathrm{cm}^{-1}$.

Fig. 3 (down) presents also the FTIR spectra in the region $1120-1000 \mathrm{~cm}^{-1}$ and the specific peaks and absorbances for ethanol at 1087 and $1047 \mathrm{~cm}^{-1}$.

Using detailed investigation, the FTIR spectra of plum brandy samples exhibited some differences. Since ethanol has a specific frequency of vibration at 1087 and $1047 \mathrm{~cm}$ 1 , these signals were compared for samples P5, M21 and PE25 (Fig. 4). The sample P5 has higher absorbance values

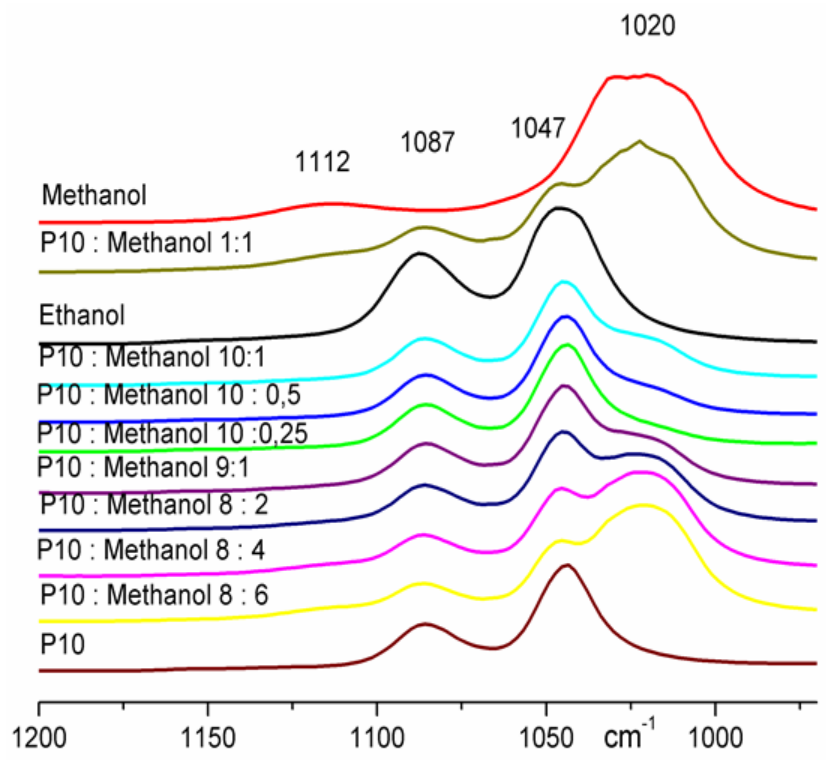

Fig. 2. Overlapped IR Spectra for methanol and ethanol in different proportion from sample P10 


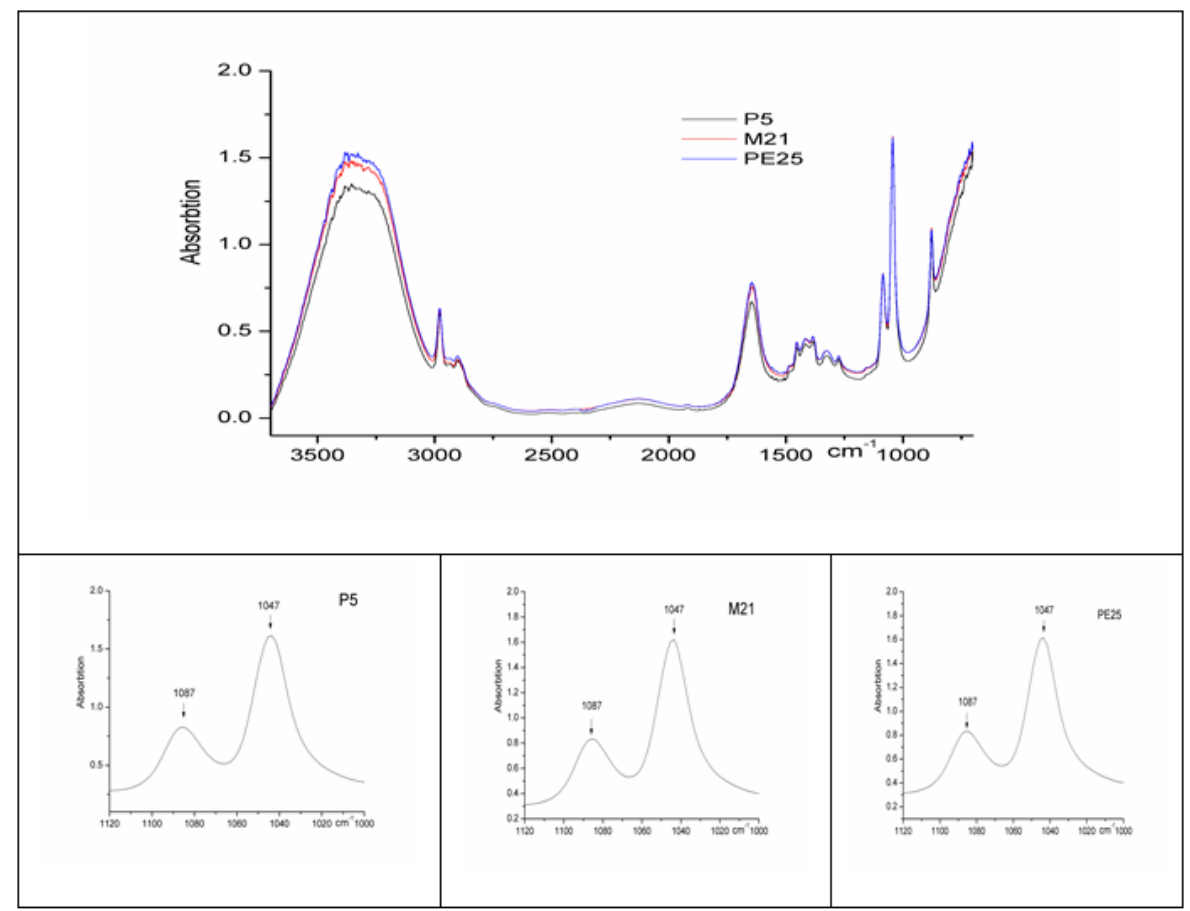

Fig. 3. Comparative IR Spectra, overlapped on domain $3500-750 \mathrm{~cm}^{-1}$, for samples: P5, M21 and PE25. Specific ethanol signals (1087 and $\left.1047 \mathrm{~cm}^{-1}\right)$ evidentiated for each sample

at these frequencies followed by sample M21 and PE25, in agreement with the concentration of ethanol reported by densimetric method (Coldea et al., 2011). While pear brandies had the lowest ethanol content, plum brandy sample had the highest, the peak area is a better parameter to evaluate the ethanol content.

\section{Principal component analysis (PCA) based on FTIR} data

The multivariate analysis of principal component analysis (PCA) based on the fingerprint of FTIR spectra which includes alcohols (methanol, ethanol) and some unfermented glucides within $1170-1000 \mathrm{~cm}^{-1}$ was carried out in order to differentiate the samples according to the biological origin and the provenience region of the tradi-

Tab. 3. The gradual evolution of methanol and ethanol signals of absorbtion at $1047,1087,1020$ and $1112 \mathrm{~cm}^{-1}$

\begin{tabular}{ccccc}
\hline Mixture & 1047 & 1087 & 1020 & 1112 \\
\hline Ethanol & 1.9539 & 1.3448 & - & - \\
P10 & 1.6468 & 0.8509 & - & - \\
\hline P10:Methanol 10:0.25 & 1.6674 & 0.8603 & - & - \\
P10:Methanol 10:0.5 & 1.6411 & 0.8585 & - & - \\
\hline P10:Methanol 10:1 & 1.6136 & 0.8487 & - & - \\
P10:Methanol 9:1 & 1.6595 & 0.8813 & - & - \\
\hline P10:Methanol 8:2 & 1.5435 & 0.8232 & 1.2428 & - \\
P10:Methanol 8:4 & 1.382 & 0.7526 & 1.5956 & - \\
\hline P10:Methanol 8:6 & 1.2761 & 0.6986 & 1.7524 & - \\
P10:Methanol 1:1 & 1.6674 & 0.8603 & - & - \\
\hline Methanol & - & - & 2.1470 & 0.4125 \\
\hline
\end{tabular}

tional brandies. There were considered absorbances which corresponded to the peak areas within the region 1170$1000 \mathrm{~cm}^{-1}$ for each sample when building the PCA score plot. Fig. 5 shows the score plot of PCA for classification of the fruit brandies using the FTIR spectra values. The PCA representation was made without normalization. As shown in Fig. 6, the first two principal components (PCs) described $92 \%$ (PC-1) and 7\% (PC-2) of the total variation, respectively. Therefore, it can be pointed that the variation of $99 \%$ could be described by the first two PCs. PC-1 is associated to methanol with the samples contain-

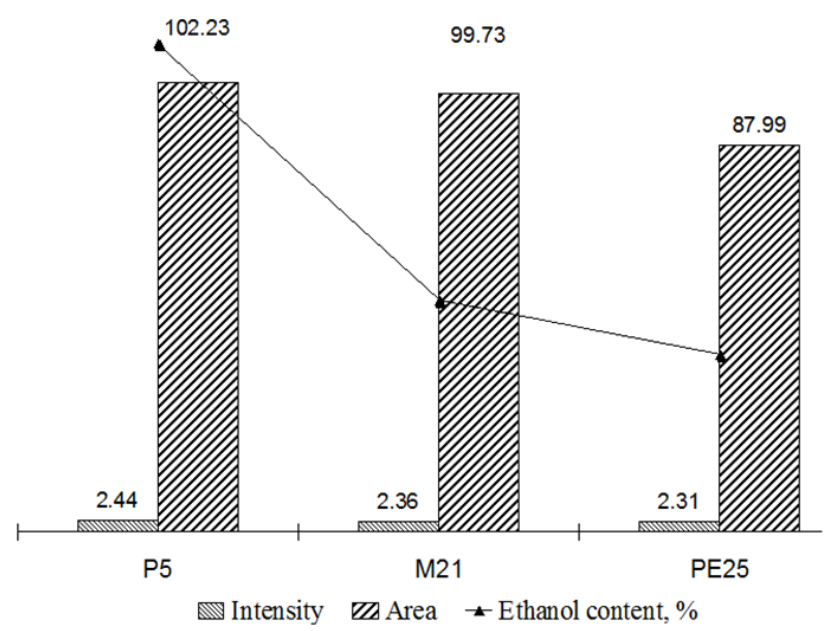

Fig. 4. Comparative values of FTIR absorption intensities and areas for signals 1047 and $1087 \mathrm{~cm}^{-1}$, as obtained by FTIR and the ethanol concentration (line- \%) as obtained by densimetric method (for sample P5, M21 and PE25) 


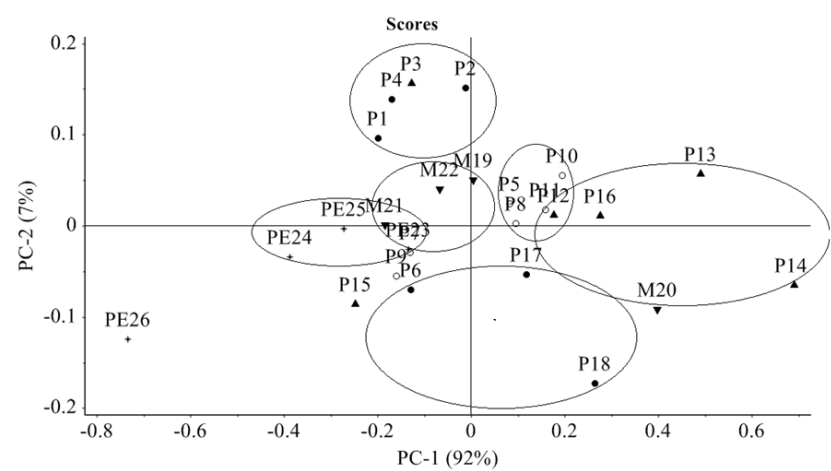

Fig. 5. Evidence of differences (scores) from analyzed beverages, depending on FTIR analysis (fingerprint zone area 1170-1000 $\mathrm{cm}^{-1}$ ) by PCA method

ing the highest methanol level having PC-1 score. PC-2, is associated with ethanol. Although almost all samples have similiar composition in alcohols, we still can distinguish six groups based on their methanol or ethanol content.

Regarding the methanol content registered by GCFID method, sample P2 had the highest content of all samples from Cluj County. In contrast, samples M19 and P10 had the lowest values. The most evident variability have the plum brandies from BN County.

Tab. 4 includes the comparison between the FTIR area signals corresponding to ethanol and the values obtained by densimetric method. There was a signifficant correlation of the results obtained for ethanol by the two methods (Fig. 6).

Correlation analysis was made between results obtained by both FTIR and densimetric methods used to determine the concentration of ethanol for all the brandies. It was used two-tailed test of significance. These results have a strong correlation $(\mathrm{R}=0.841)$ for the all samples.

Calibration and validation of PLS procedure for methanol

By applying the PLS regression for methanol calibration curve (Fig. 7 and Tab. 2) we were able to predict its content in brandies. The predicted concentrations of methanol were obtained based on FTIR absorbance at $1020 \mathrm{~cm}^{-1}$ (g/100 g fruit brandy) and transformed into $\mathrm{g} / 100 \mathrm{mg}$ anh. alc.

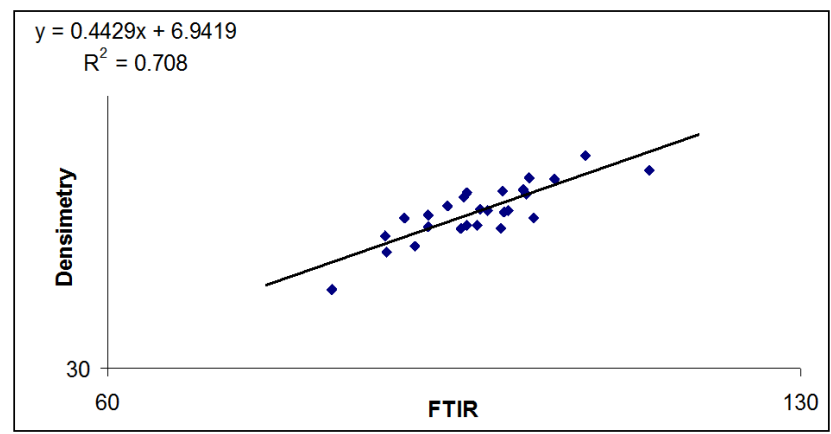

Fig. 6. Correlation curve established for the etahnol concentrations obtained by two methods (densimetry and FTIR). Correlation coefficient $=0.708(p<0.05)$

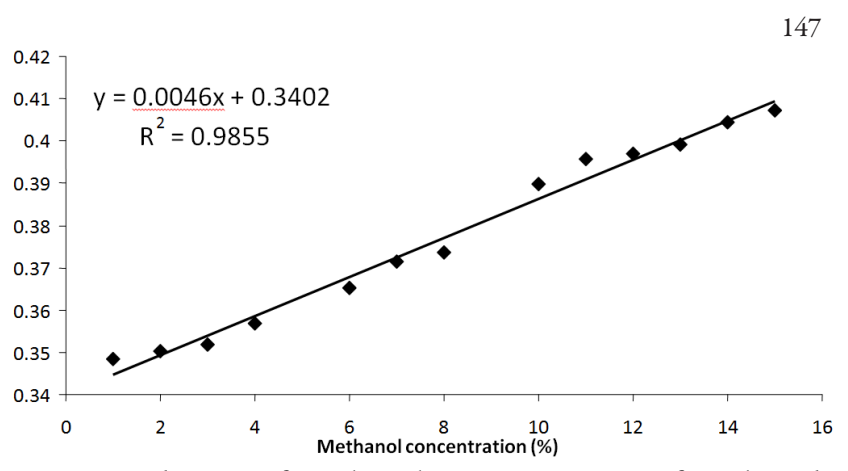

Fig. 7. Prediction of methanol concentration in fruit brandy samples, by appling the Partial Least Squares (PLS) Regresion: Calibration curve with methanol at $1020 \mathrm{~cm}^{-1}$ (on methanol concentration interval 1-15\%)

Tab. 5 exhibits the correlations between the values for methanol content, for the set of all 26 samples, as obtained by the two methods applied, FTIR (predicted values) and GC-FID (experimental values) (Coldea et al., 2011). A mean ratio of $1.1176 \pm 0.2402$ was obtained between the values obtained by GC-FID and FTIR, demonstrating the good prediction $(p<0.05)$ performd by FTIR technique.

Tab .5. Correlations between the values of methanol concentrations for obtained from the two methods FTIR and GC-FID

\begin{tabular}{|c|c|c|c|}
\hline Sample & $\begin{array}{c}\text { FTIR } \\
\text { (predicted values) }\end{array}$ & $\begin{array}{c}\text { GC-FID } \\
\text { (Actual values) }\end{array}$ & $\begin{array}{c}\text { Ratio } \\
\text { GC-FID/FTIR }\end{array}$ \\
\hline P1 & 851.91 & 1077.59 & 1.2649 \\
\hline P2 & 818.39 & 1266.97 & 1.5481 \\
\hline P4 & 850.40 & 954.31 & 1.1221 \\
\hline $\mathrm{P} 6$ & 868.18 & 1244.35 & 1.4332 \\
\hline P17 & 861.54 & 1100.76 & 1.2776 \\
\hline P18 & 906.28 & 953.69 & 1.0523 \\
\hline P3 & 843.26 & 964.96 & 1.1443 \\
\hline P12 & 815.72 & 901.39 & 1.1050 \\
\hline P13 & 758.35 & 1073.70 & 1.4158 \\
\hline P14 & 819.42 & 913.01 & 1.1142 \\
\hline P15 & 926.54 & 765.86 & 0.8265 \\
\hline P16 & 795.93 & 953.73 & 1.1982 \\
\hline P5 & 803.50 & 857.71 & 1.0674 \\
\hline P7 & 841.05 & 504.18 & 0.5994 \\
\hline P8 & 804.21 & 999.81 & 1.2432 \\
\hline P9 & 875.00 & 1256.41 & 1.4358 \\
\hline $\mathrm{P} 10$ & 755.55 & 450.50 & 0.5962 \\
\hline P11 & 825.07 & 954.12 & 1.1564 \\
\hline M19 & 822.32 & 597.64 & 0.7267 \\
\hline M20 & 866.61 & 1189.29 & 1.3723 \\
\hline M21 & 878.57 & 1020.89 & 1.1619 \\
\hline M22 & 830.68 & 810.97 & 0.9762 \\
\hline PE23 & 881.89 & 973.61 & 1.1040 \\
\hline PE24 & 923.37 & 818.34 & 0.8862 \\
\hline PE25 & 883.67 & 880.69 & 0.9966 \\
\hline PE26 & 1045.89 & 1290.06 & 1.2334 \\
\hline \multicolumn{3}{|c|}{ Average ratio } & 1.1176 \\
\hline \multicolumn{3}{|c|}{ SD } & 0.2402 \\
\hline
\end{tabular}


148

By comparison with GC-FID analysis, the obtained values for methanol, based on the forecast calibration and FTIR spectra, were of the same order, from 0 to $1.2 \%$ anh. alc. Among all samples, the minimum concentration of methanol was determined in sample P10, and the maximum in PE26, by both FTIR and GC-FID methods.

We noticed also differences among the type of brandy: the methanol from apple brandies was better correlated $(R=0.874)$, followed by the pear brandies $(R=0.860)$ and no correlations for the plum brandies $(R=0.213)$. A high correlation was in the case of MM plum brandies $(\mathrm{R}=0.621)$. Unsignificant correlations were registered in the case of CJ plum brandies $(\mathrm{R}=-0.565)$ and $\mathrm{BN}$ plum brandies $(R=-0.911)$. The most appropiate results for methanol obtained by the two methods were those for plum distillate from Maramureş County. The standard deviation of values obtained by FTIR method were much lower than those by GC-FID. Finally we conclude that FTIR technique applied for methanol quantification can predict reliable results and in good correlation with GCMS technique.

\section{Conclusions}

FTIR method can be useful not only for determing the methanol and ethanol content in extract-free samples, but also to evaluate the ratio between these two volatile components in brandies. FTIR/PLS offers valuable advantages when choosing versus conventional methods. Their importance it is justified by being a rapid, efficient and non-destructive tool for screening alcoholic beverages. Besides the quantitative PLS analysis, the PCA classification of data obtained by FTIR spectra becomes important for authenticity control of the provenience region and the type of the fruit brandy.

\section{Acknowledgements}

This work has benefited from financial support through the 2010 POSDRU/ 89/1.5 /S 52432 project, „Organizing the National Interest Postdoctoral School of Applied Biotechnologies with Impact on Romanian Bioeconomy", project co-financed by the European Social Fund through the Sectoral Operational Programme Human Resources Development 2007-2013.

\section{References}

Arzberger U, Lachenmeier DW (2008). Fourier transform infrared spectroscopy with multivariate analysis as a novel method for characterizing alcoholic strength, density, and total dry extract in spirits and liqueurs. Food Anal Methods $1(1): 18-22$.

Ashok PC, Praveen BB Dholakia K (2011). Near infrared spectroscopic analysis of single malt Scotch whisky on an optofluidic chip. Opt Express 19(23):22982-22992.

Borges Sivanildo S, Rejane M Frizzarin, Boaventura F Reis
(2006). An automatic flow injection analysis procedure for photometric determination of ethanol in red wine without using a chromogenic reagent. Anal Bioanal Chem 385(1):197-202.

Bozkurt SS, Merdivan E, Benibol Y (2010). A fluorescent chemical sensor for ethanol determination in alcoholic beverages. Microchim Acta 168(1-2):141-145.

Coldea TE, Socaciu C, Pârv M, Vodnar D (2011). Gas-chromatographic analysis of major volatile compounds found in traditional fruit brandies from Transylvania, Romania. Not Bot Horti Agrobo 39(2):109-116.

Da Costa RS, Santos SRB, Almeida LF, Nascimento ECL, Pontes MJC, Lima RAC, Simões SS, Araújo MCU (2004). A novel strategy to verification of adulteration in alcoholic beverages based on Schlieren effect measurements and chemometric techniques. Microchem J 78(1):27-33.

Diban N, Voinea OC, Urtiaga A, Ortiz I (2009). Vacuum membrane distillation of the main pear aroma compound: experimental study and mass transfer modeling. J Membrane Sci 326:64-75.

Gallignani M, Ayala C, Brunetto MD, Burguera JL, Burguera M (2005). A simple strategy for determining ethanol in all types of alcoholic beverages based on its on-line liquid-liquid extraction with chloroform, using a flow injection system and Fourier transform infrared spectrometric detection in the mid-IR. Talanta 68(2):470-479.

García-Llobodanin L, Ferrando M, Güell C, López F (2008). Pear distillates: influence of the raw material used on final quality. Eur Food Res Technol 228(1):75-82.

Hernández-Gómez LF, Úbeda-Iranzo J, García-Romero E, Briones-Pérez A (2005). Comparative production of different melon distillates: chemical and sensory analyses. Food Chem 90:115-125.

Joshi VK, Sandhu DK (2000). Influence of ethanol concentration, addition of spices extract, and level of sweetness on physico-chemical characteristics and sensory quality of apple vermouth. Braz Arch Biol Techn 43(5):537-545.

Lachenmeier DW (2007). Rapid quality control of spirit drinks and beer using multivariate data analysis of Fourier transform infrared spectra. Food Chem 101(2):825-832.

Leopold LF, Leopold N, Diehl HA, Socaciu C (2011). Quantification of carbohydrates in fruit juices using FTIR spectroscopy and multivariate analysis. Spectrosc Int J 26(2):93104.

López-Vázquez C, Bollaín MH, Berstsch K, Orriols I (2010). Fast determination of principal volatile compounds in distilled spirits. Food Control 21:1436-1441.

Mansor TST, Man YBC, Rohman A (2011). Application of fast gas chromatography and fourier transform infrared spectroscopy for analysis of lard adulteration in virgin coconut oil. Food Anal Method 4(3):365-372.

Mehrotra R, Gupta A, Nagarajan R (2005). NIR spectroscopy and fiber optic probe for determination of alcohol, sugar 
and tartaric acid in alcoholic beverages. J Sci Ind Res India 64(2):134-137.

Nagarajan R, Mehrotra R, Bajaj MM (2006). Quantitative analysis of methanol, an adulterant in alcoholic beverages, using attenuated total reflectance spectroscopy. J Sci Ind Res India 65(5):416-419.

Pérez-Ponce A, Rambla FJ, Garrigues JM, Garrigues S, de la Guardia M (1998). Partial least-squares fourier transform infrared spectrometric determination of methanol and ethanol by vapour-phase generation. Analyst 123(6):12531258.

Pontes MJC, Santos SRB, Araújo MCU, Almeida LF, Lima RAC, Gaião EN, Souto U (2006). Classification of distilled alcoholic beverages and verification of adulteration by near infrared spectrometry. Food Res Int 39(2):182-189.

Regulation (EC) No 110/2008 of the European Parliament and of the Council of 15 January 2008 on the definition, description, presentation, labelling and the protection of geographical indications of spirit drinks and repealing Council Regulation (EEC) No 1576/89. Official Journal of the European Union, 51, L39, 16-54.
149

Rohman A, Man YBC, Riyanto S (2011). Authentication analysis of red fruit (Pandanus Conoideus Lam) oil using FTIR spectroscopy in combination with chemometrics. Phytochem Analysis 22(5):462-467.

Tešević V, Nikićević N, Milosavljević S, Bajić D, Vajs V, Vučković I, Vujisić L, Đorđević I, Stanković M, Veličković M (2009). Characterization of volatile compounds of "Drenja", an alcoholic beverage obtained from the fruits of cornelian cherry. J Serb Chem Soc 74(2):117-128.

Wang ML, Choong YM, Su NW, Lee MH (2003). A rapid method for determination of ethanol in alcoholic beverages using capillary gas chromatography. J Food Drug Anal 11(2):133-140. 